\title{
CONSIDERAÇÕES CRÍTICAS SOBRE A PESQUISA NO CAMPO DA MANUALÍSTICA ESCOLAR, APOS 20 ANOS DA FUNDAÇÃO DO CENTRO DE PESQUISA MANES
}

Critical considerations on School Textbook Research, 20 years after the Foundation of the Manes Research Center

Consideraciones críticas sobre la investigación en el campo de la Manualistica Escolar, a 20 años de la fundación del Centro de Investigación Manes

\begin{abstract}
Resumo
O artigo apresenta um balanço crítico das pesquisas com livro didático, após 20 anos da criação do Centro de Investigações MANES, apontando experiências adquiridas nesse processo de consolidação da pesquisa no campo da manualística na Espanha.
\end{abstract}

PALAVRAS-CHAVE: História da Educação. Pesquisas. Livros Didáticos.

\begin{abstract}
The article presents a critical revision of the research on textbooks 20 years after of the creation of the MANES Research Center, highlighting the experiences acquired in this process of consolidation of the field of textbook research in Spain.
\end{abstract}

KEYWORDS: History of Education. Research. Textbooks.

\section{Resumen}

El artículo presenta una revisión crítica de las investigaciones sobre el libro de texto después de 20 años de creación del Centro de Investigación MANES, destacando las experiencias adquiridas en este proceso de consolidación de la investigación en el campo de la manualística en España.

PALABRAS CLAVE: Historia de la Educación. Investigación. Manuales Escolares.

\section{INTRODUÇÃO}

\footnotetext{
${ }^{1}$ N.T.: Traduzido para o português por Marcus Wagner Antunes Loureiro. Versão em espanhol intitulada "Consideraciones críticas sobre la investigación en el campo de la manualistica escolar a 20 años de la fundación del Centro de Investigación MANES" e publicado como capítulo no livro: La historia de la cultura escolar en Italia y en Espana: balance y perspectivas, organizado por Meda e Badanelli (2013).

${ }^{2}$ Doutora em Ciências da Educação, professora do Departamento de História da Educação e Educação Comparada na Universidad Nacional de Educación a Distancia (UNED), em Madri. Presidente da Sociedade Espanhola de História da Educação no período 2013-2017, e diretora do Centro de Investigação MANES (Manuales Escolares), da UNED. End.: Rua Juan Del Rosal, 14, Madrid, Espanha, CEP 28040. Tel.: (0034) 913986988. Email: <gossenbach@edu.uned.es>.
} 
O título deste artigo tem uma intenção claramente provocativa. Responde a nossa percepção, que compartilhamos com outros estudiosos dos textos escolares, de que algumas das linhas de pesquisa empreendidas no campo da manualística têm "tocado fundo"; tem esgotado suas possibilidades de contribuir a partir do campo da história para uma teoria sobre a cultura escolar ${ }^{3}$. Esta forma de olhar as coisas leva implícito, de alguma maneira, um balanço nem sempre satisfatório da pesquisa no campo da manualística levada em conta na Espanha nas últimas décadas, cuja evolução descreve Agustín Escolano neste mesmo dossiê. Entretanto, nossa intenção não é outra se não a de servir de estímulo para refletir sobre questões metodológicas que afetam a pesquisa histórica sobre os textos escolares, que nos permitam avançar em novas direções e não dar por "esgotadas" as possibilidades que oferece o estudo desta complexa fonte histórica (DEPAEPE; VAN GORP, 2009).

Não pretendemos, certamente, menosprezar a importância dos textos escolares como fonte para a pesquisa histórico-educativa, cujo estudo fez possível que desde a reflexão histórica evitássemos "o atentado de abandonar a escola", como vieram fazendo muitos "teóricos, experimentalistas e didatas" e que nos aproximássemos dos manuais "como alavanca para levantar a lousa dos discursos de filosofia escolástica que haviam enterrado o latejo real da história da escola". Se a escola foi tachada tantas vezes de "livresca" é porque o livro escolar foi desde sempre um dispositivo fundamental para a transmissão de saberes e a organização das práticas escolares. Não é de se estranhar, portanto, que desde que a historiografia da educação pôs seu foco na cultura escolar os primeiros objetos de estudo tenham sido os velhos livros didáticos e que estes abundem formando parte do patrimônio de museus pedagógicos, coleções e bibliotecas.

Não deve parecer estranho que depois de vinte anos pesquisando sobre manuais escolares no seio do Centro de Pesquisa MANES $^{5}$ (Manuales Escolares), nos detenhamos a fazer um balanço crítico do trabalho realizado dentro de um campo que teve um boom ao longo destas décadas e que deu de si um corpo muito extenso de pesquisas de caráter histórico que tem utilizado os textos escolares como fonte. A criação em torno do MANES de uma ampla rede internacional de pesquisadores europeus e latino-americanos dedicados a manualística escolar não é alheia a uma ampla produção historiográfica que se reuniu no repertório bibliográfico BIBLIOMANES, acessível na página da web do referido centro de pesquisa ${ }^{6}$.

Nas páginas seguintes, tentaremos sistematizar nossas observações sobre algumas vias que consideramos esgotadas e as novas perspectivas que se abrem à investigação sobre os textos escolares, acrescentando, em alguns casos, sugestões sobre temas emergentes, que valeria a pena explorar.

\footnotetext{
${ }^{3}$ Agradeço a Kira Mahamud pelas observações durante a elaboração do presente texto.

${ }^{4}$ Estas expressões tomei de um breve texto autobiográfico inédito do Professor Federico Gómez R. de Castro, fundador do Centro de Pesquisa MANES, escrito por ocasião do $20^{\circ}$ aniversário de criação do referido centro (novembro de 2012).

5 N.T.: Centro de Investigacíon MANES, Manuales Escolares - criado em 1992 pela Universidad Nacional de Educación a Distancia (UNED), com sede em Madrid - Espanha. É um centro de investigação interuniversitário dedicado ao estudo histórico dos livros didáticos da Espanha, Portugal e América Latina, especialmente nos séculos XIX e XX. Disponível em: <http://www.centromanes.org>. Acesso em: 26 jun. 2017.

${ }^{6}$ BIBLIOMANES é uma lista bibliográfica que reúne livros, capítulos de livros, artigos, comunicações em congressos e outros textos sobre manualística produzidos em diversos países do mundo, com especial atenção ao âmbito espanhol e latino-americano. Disponível em: http://www.centromanes.org/?page_id=451 [acesso em 13/01/2018].
} 


\section{0 inventário das fontes}

Talvez uma parte de nossa insatisfação ou inquietação sobre o alcance da pesquisa nos primeiros vinte anos do MANES tenha a ver com o imenso esforço investido nas tarefas de recompilação e catalogação dos textos escolares e da legislação e planos de estudos que lhes regularam, tarefas que deviam preceder necessariamente à própria pesquisa. Todas estas ações deram lugar ao que às vezes se confundiu com a própria identidade do pesquisador e de seu trabalho, obrigando-lhe a dedicar muito tempo e energia em trabalhos mais próprios de documentalistas e bibliotecários e levando-lhe a caminhos já praticamente esgotados. Quando se começou a caminhar pela via da manualística escolar não existia na Espanha, nem nos países em que o MANES estabeleceu seus primeiros acordos de colaboração, um censo da produção de livros escolares. Além disso, estes não eram de fácil acesso nas bibliotecas nem nas próprias escolas, pois os textos escolares nunca receberam o mesmo tratamento que outros tipos de livros na hora de serem guardados e registrados nas coleções bibliográficas. É possível fazer um balanço muito positivo dos alcances conseguidos neste sentido, podendo afirmar que, ao menos no caso da Espanha, conhecemos já bastante bem a produção de livros escolares nos últimos séculos, assim como as principais casas editoriais que os produziram e comercializaram em nível local e nacional ${ }^{7}$. Por outro lado, todos estes trabalhos auxiliares da pesquisa impulsionaram a criação de importantes coleções públicas e privadas de textos escolares, que permitiram salvaguardar esta importante parte do patrimônio histórico-educativo.

Não podemos afirmar, contudo, que a elaboração de uma grande base de dados e a discussão em torno dos critérios para a catalogação dos textos escolares tenha carecido de interesse para a pesquisa, pois a "estratégia de organização" das fontes é uma decisão que implica critérios historiográficos que não podem ser elucidados, e que exigem uma "reflexão semântica" prévia. Como afirmou Santiago Aragón, a etapa de reflexão semântica é o mais importante durante a concepção de uma base de dados e implica a compreensão do âmbito que se quer informatizar, dos objetos que o constituem e das relações que podem ter uns com os outros. Trata-se da elaboração do esquema conceitual, e que permite a representação lógica da realidade que se pretende transcrever na base de dados (ARAGÓN, 2009) ${ }^{8}$. Em geral, bases de dados bibliográficos contêm campos destinados a recolher informações associadas à procedência e a descrição do livro, mas também dados que implicam uma determinada interpretação do mesmo, selecionando certos elementos do documento como critério para sua catalogação, em detrimento de outros. Com ele correríamos o risco de

\footnotetext{
${ }^{7}$ Como produto das tarefas de catalogação dos textos escolares se criou a Base de Dados MANES, acessível em http://www.centromanes.org:8080/ [consulta em 13/01/2018].

${ }^{8}$ Trabalho inédito apresentado no Seminário interno de projeto Ciencia y educación en los institutos madrileños de enseñanza secundaria a través de su patrimonio cultural (1837-1936). Aragón refere-se neste trabalho a alguns autores que abordaram a questão da reflexão semântica na concepção de uma base de dados: C. Delobel, C. Lecluse, P. Richard, Bases de données: des systèmes relationnels aux systèmes à objets, Paris, Inter Éditions, 1991; M. Humbert, Les bases de données, Paris, Hermes, 1991. Um exemplo de "reflexão semântica"em torno da criação de uma base de dados de manuais escolares, pode se ver em M. Di Giovanni, Esigenze storiografiche e risorse elettroniche nella costruzione di una banca dati specializzata, em G. Bandini, P. Bianchini (a cura di), Fare storia in rete, Roma, Carocci, 2007, p. 106117.
} 
condicionar ou dirigir em uma direção determinada a pesquisa sobre os textos escolares, impedindo ou ocultando outros possíveis olhares sobre esta fonte histórica.

A partir de 2005, ao internacionalizar os esforços de catalogação de textos escolares, introduzindo em uma mesma base de dados livros de diferentes nacionalidades, tivemos que conceber uma necessária simplificação dos campos da ficha básica de catalogação, com o fim de prescindir de possíveis peculiaridades nacionais e buscar algum denominador comum que fosse válido para todos os livros escolares catalogados (OSSENBACH et al., 2006). Em contrapartida, a internacionalização da pesquisa e da diversidade de pontos de vista permitiram, como destacam M. Depaepe e A. Van Gorp, vislumbrar melhor a complexidade do objeto de estudo (o livro de texto) e pôr sobre a mesa a discussão em torno da pergunta de se epistemologicamente é possível deduzir características universais do livro escolar (DEPAEPE; VAN GORP, 2009, p. 18). O resultado final de todo este esforço foi a criação de uma importante ferramenta, de forma mais asséptica possível, que facilita enormemente o acesso às fontes de pesquisa e que consistem em uma base de dados de textos escolares da Espanha, Portugal e vários países da América Latina, assim como, em menor medida, da Bélgica. Esta base de dados foi incorporada recentemente a uma base de dados supranacional (International Textbook Catalogue), que exigiu definir previamente as equivalências entre alunos dos campos mais comuns na catalogação de textos escolares dos diferentes países (especialmente os campos dedicados à matéria e ao nível escolar) ${ }^{9}$. Esta via de trabalho, que podemos considerar completa, pode abrir outra porta à digitalização e a criação de bibliotecas virtuais de textos escolares, que ampliem as possibilidades de consulta das coleções especializadas de livros de texto, nem sempre de fácil acesso ${ }^{10}$, e que tornem possível que a manualística entre na chamada "história digital", com suas indiscutíveis vantagens, ainda que também com seus riscos (BADANELLI; OSSENBACH, 2010).

\section{A análise de conteúdo dos textos escolares}

O início da pesquisa sobre os textos escolares pressupôs a necessidade de conhecer o que havia dentro desses livros que se inventariavam e catalogavam, de tal maneira que uma perspectiva privilegiada de estudo foi durante todos estes anos a análise do conteúdo dos livros de texto, especialmente daqueles conteúdos com uma importante carga ideológica (nacionalismo, influência religiosa, estereótipos de gênero e raça, entre muitos outros). Além disso, vários destes trabalhos foram enriquecidos com interessantes análises de discurso ou de linguagem iconográfica utilizados na transmissão destes conteúdos. As contribuições que este tipo de pesquisa deram ao campo da manualística são inquestionáveis, pois não só nos permitiram ter uma ideia bastante clara do que os livros contêm, de qual aspecto material tem, de como se expressam e de como evoluíram ao longo da história, mas também permitiram compreender melhor a escola como transmissora de conhecimentos, valores e ideologia.

\footnotetext{
${ }^{9}$ O International Textbook Catalogue é um projeto conjunto do Georg Eckert Institute for International Textbook Research (Alemania), a Universidade de Torino (Italia) e o Centro de Investigação MANES (Espanha) [http://itbc.gei.de/].

10 Algumas importantes bibliotecas digitais de textos escolares são as de Georg Eckert Institute for International Textbook Research (Alemanha), acessível em http://gei-digital.gei.de/viewer/, assim como a da Biblioteca Nacional de Mestres de Buenos Aires (Argentina), acessível em http://www.bnm.me.gov.ar/catalogos/index.php
} 
Contudo, muitas dessas pesquisas não levaram em conta a representatividade dos textos analisados para poder inferir o possível impacto de determinados conteúdos na formação das mentalidades ou na construção subjetiva do conhecimento, questão que, a nosso ver, é de enorme relevância. O estudo de amostras muito pequenas de livros escolares (frequentemente o estudo de um único livro como objeto de pesquisa), ou de livros de editoras de pouca difusão, tomados como fonte, podem gerar resultados irrelevantes para a pesquisa ou, pior ainda, conclusões que de alguma maneira deturpam o verdadeiro impacto de um manual em um momento ou circunstância dada ${ }^{11}$.

É notório que desde o momento em que se puseram a disposição dos pesquisadores dos textos escolares através de catálogos, coleções e bibliotecas virtuais, foi facilitado seu uso como fonte muito "útil" para elaborar pequenas pesquisas sobre o conteúdo de alguns livros, que servem como comunicações em congressos e reuniões científicas, ou como ensaios nos cursos universitários. Este tipo de trabalho com frequência não consideraram os critérios mínimos para selecionar amostras representativas de acordo com alguns indícios básicos como o número de edições dos livros estudados, a relevância e grau de difusão das edições, seu caráter regional ou não, etc. A proliferação deste tipo de pesquisa, acreditamos, não beneficia a manualística.

Não obstante, a análise de conteúdo segue sendo uma frutífera linha de pesquisa, se se considerar as precauções metodológicas que fizemos alusão. Ainda há muito por fazer, sobretudo no campo dos textos de ciências naturais, já que a pesquisa primou pelo estudo do conteúdo dos livros de ciências humanas e sociais, onde pode ser mais evidente a carga ideológica ${ }^{12}$.

Por outro lado, um campo ainda relativamente pouco explorado em torno da análise de conteúdo diz respeito à história das disciplinas escolares. Antonio Viñao Frago insistiu em vários de seus trabalhos na necessidade de vincular a manualística com a história das disciplinas, entendendo que nos textos escolares fica plasmado um "código disciplinar", quer dizer, uma seleção de conteúdos de uma matéria que se formaram historicamente como socialmente valiosos, que se convertem em cânones e se fixam ou sedimentam como matérias a transmitir no ensino ${ }^{13}$. Este conteúdo formalizado (assim como o procedimento para seu ensino) aparece nos textos escolares sistematizado e sequenciado, sendo objeto de um "trânsito" desde os espaços sociais de um determinado conhecimento ou saber até o "espaço social da escola". Um trânsito que, ao traduzir esse conhecimento em uma questão de aprendizagem escolar implica uma troca de ordenamento mental do mesmo a fim de adaptar-se às exigências do horário escolar, às concepções sobre a infância e a adolescência, e às convenções e rotinas do ensino (ou seja, à cultura escolar), que impõem tal conhecimento no currículo escolar (VIÑAO FRAGO, 2006a y 2006b) ${ }^{14}$. Depaepe e Van Gorp definem estas

\footnotetext{
${ }^{11}$ Ainda que não se trate de um trabalho de pesquisa propriamente, um caso que exemplifica claramente as consequências que podem ter o estudo de uma mostra pouco representativa de textos escolares foi o Informe sobre os textos e cursos de história nos centros de ensino médio que a Real Academia de História da Espanha realizou no ano de 2000, embasado na análise de uns poucos livros escolares de muito escassa difusão que, porém, engendrou um grande debate nacional sobre o ensino das Humanidades na escola secundária. Pode acessar-se o texto do informe em <http://servidormanes.uned.es/mciud/documentos/debate_humanidades.htm> .

${ }^{12}$ Um estudo interessante sobre livros didáticos de Física e Química é o de González Clouté (2011).

${ }^{13}$ Um interessante trabalho sobre a conformação do cânone literário nos manuais de Língua e Literatura Espanhola do período 1970-2006 em Mora Luna, 2012.

${ }^{14}$ Segundo Viñao Frago, a história dos manuais escolares só tem sentido, desde a perspectiva da cultura escolar (quer dizer, para entender o que significa na cultura escolar o livro de texto), no seio ou na relação com as respectivas disciplinas acadêmicas (já que se trata de saberes acadêmicos, de tarefas ou de
} 
transformações como um processo que vai desde a "elementarização" do conhecimento (Elementarisierung) e sua "didatização" (Didaktisierung) à sua "psicologização" (Psychologisierung) e "infantilização" (Infantilisierung), produzindo-se esta última transformação por influência da pedagogia da Escola Nova (DEPAEPE; VAN GORP, 2009, p. 11 e 18-19).

Outro aspecto vinculado com a história das disciplinas escolares é o estudo, por meio do conteúdo dos textos escolares, das resistências ou atrasos que se produzem na apropriação dos avanços científicos na cultura da escola (HERNÁNDEZ LAILLE, 2010). Igualmente, os manuais escolares permitem estudar os processos de especialização disciplinar produzidos historicamente a partir da fragmentação do conhecimento enciclopédico da escola tradicional.

Finalmente, uma linha de pesquisa de interesse é a que relaciona o currículo prescrito (os planos e programas de estudo que emanam das autoridades competentes na matéria) com o conteúdo dos textos escolares (currículo editado), com o objetivo de explorar possíveis convergências e dissidências. Para o caso da Espanha, considerando a ausência de programas oficiais para as escolas em alguns períodos, e o monopólio que tradicionalmente teve o livro de texto nas atividades de sala de aula, surpreende como os livros escolares (e portanto, os autores ou editores), muito mais que as prescrições curriculares, determinaram em muitas ocasiões o que se ensina nas escolas.

\section{A contribuição da manualística para a história da cultura escolar}

Enquanto no inventário e na análise de conteúdo dos textos escolares foram realizados importantes avanços, ainda são escassas as contribuições da manualística para a história da cultura escolar, ou seja, para a compreensão dos processos de ensino e aprendizagem na sala de aula e das tradições e regularidades sedimentadas ao longo do tempo na prática das escolas. É neste âmbito que a manualística surge com força nos últimos anos, abrindo novos horizontes para a pesquisa, mas ao mesmo tempo, apresentando muitas dificuldades. Por um lado, não é fácil encontrar evidências da forma em que se tem utilizado os textos escolares nas salas de aula, por outro lado, é preciso indagar sobre as formas de apropriação dos discursos e práticas contidos nos textos escolares por parte dos sujeitos que aprendem, entre outras coisas para conhecer como os conhecimentos aprendidos se transformam em determinadas condutas e quais mediações se estabelecem entre o texto escolar e o discente ${ }^{15}$. É pertinente neste sentido, considerar a advertência do grande estudioso das práticas de leitura Roger Chartier de que "a questão essencial que deve permear toda história do livro, da edição e da leitura é o processo mediante o qual os leitores e expectadores ou ouvintes dão sentido aos textos que se apropriam" (CHARTIER, 2000, p. 169). O texto é, definitivamente, uma construção incompleta se não for lido, o texto é o que seus leitores fazem dele. Nas palavras de Humberto Eco, a interpretação de um texto "está prevista

atividades). Junto ao código disciplinar que se plasma nos livros de texto, Viñao Frago alude a outros elementos que configuram uma disciplina escolar; entre outros aspectos, se refere a criação de um campo delimitado por um determinado grupo de professores no qual se definem os critérios de credibilidade para o acesso ao mesmo, convertendo à disciplina escolar em elemento chave da profissionalização do docente.

${ }^{15}$ Carsten Heinze define os livros de texto como um ponto de intersecção entre os discursos e as práticas de ensino (HEINZE, 2010, p. 122). 
em seu projeto original" (ECO, 1999, p. 79). Como nos adverte Kira Mahamud em sua recente tese de doutorado, que consideramos um dos esforços mais importantes de renovação metodológica na pesquisa sobre textos escolares no seio do Centro de Pesquisa MANES, “como podemos ignorar, não considerar, nem sequer nos aproximar teoricamente da percepção dos discursos destes textos por parte da infância? Este tem sido tradicionalmente um dos pontos deficientes da pesquisa sobre os manuais escolares, junto à ausência ou pobreza da evidência do uso dos mesmos... é necessário abrir caminho para a comprovação da entrada do manual na aula, do seu uso pelo professor e dos processos de recepção das mensagens textuais e discursivas pela criança" (MAHAMUD, 2012, p. 37).

O grande dilema que propõe a manualística é o fato de que se por um lado os livros de texto parecem ser uma fonte inesgotável do conhecimento sobre a prática pedagógica, não se pode deixar de considerar que "por trás da imagem da escola que alguém possa evocar ao examinar os livros escolares, há uma complexa história da prática real na sala de aula" (ROCKWELL, 2004, p. 327). Mas, como adverte Dominique Julia (1995, p. 358), a tarefa de reconstruir a vida em sala de aula requer a descrição de práticas culturais que raras vezes deixam pegadas, e que com frequência teremos que nos contentar com aproximações e sérios limites para a pesquisa.

Uma das estratégias para nos aproximar do conhecimento das práticas relacionadas ao uso dos textos escolares é o de combinar várias fontes que apontem indícios e permitam reconstruir o contexto da sala de aula: cadernos, fontes orais, diários de professores e alunos, relatório de inspeção, etc. O trabalho que apresentam Ana Maria Badanelli e Kira Mahamud neste dossiê é um pequeno ensaio do que este tipo de combinação de fontes pode dar de si para o conhecimento da cultura escolar, interrelacionando livros e cadernos escolares junto com relatos orais pertencentes ao universo escolar mais concreto, felizmente guardado em um arquivo familiar. É por esta via que cremos que se deve avançar para interpretar o rol dos textos escolares na "gramática da escola".

\section{A reconstrução dos contextos como exigência para a pesquisa sobre os textos escolares}

De alguma forma, todos os problemas metodológicos que nos referimos nestas páginas conduzem a necessidade de uma correta contextualização dos textos escolares utilizados como fonte de pesquisa, condição que consideramos imprescindível para evitar o "esgotamento" da pesquisa histórica sobre os manuais escolares. Uma abordagem metodológica unidimensional, enfocada só no livro de texto e circunscrito a seu conteúdo conduzirá a uma perspectiva muito limitada, já que por este procedimento os efeitos e os significados do texto escolar ficam supervalorizados, enquanto os contextos que dão significado são excluídos (HEINZE, 2010, p.124). A manualística deve ir abandonando sua "insularidade" (DEPAEPE; SIMON, p. 65), se liberando um pouco de suas próprias fontes primárias e encaixando em um todo mais amplo (DEPAEPE; VAN GORP, 2009, p. 18).

Desde os historiadores do livro e da leitura, que nos demandam a consideração do contexto que condiciona a recepção dos textos e do sentido que os leitores incorporam ao que leem, até os historiadores do pensamento ou das ideias, que nos 
apontam o imperativo de recuperar os contextos de produção das obras clássicas do pensamento, mas também sua recepção e interpretação por parte dos leitores, o chamado "giro contextual" se instalou definitivamente na pesquisa que tem como objeto o estudo dos textos e, logicamente, também, no dos textos escolares (BOCARDO, 1996; VIÑAO FRAGO, 1996).

Por outro lado, considerando que os textos escolares têm sido instrumentos essenciais das práticas escolares, e que estas práticas são definitivamente práticas culturais, a etnografia trás também contribuições de grande interesse para o campo da manualística (etnografia da escola) (ROCKWELL, 2009). A etnografia, na hora de procurar reconstruir práticas culturais, alude também, à necessidade da recriação dos contextos como parte essencial do que em etnografia se entende como "trabalho de campo":

\begin{abstract}
A pretensão que anima o trabalho de campo é a apreensão da totalidade. Esta recebe nomes genéricos, globalizantes: o contexto, a história, a sociedade, a cultura [...] a noção de contexto faz conceber que o acesso ao significado de um fenômeno social não se alcança se a não ser interrogando-o em um conjunto de relações com outros, e apreciando esse conjunto de relações como um todo. Outras noções, como estrutura ou sistema, tem recriado a noção de totalidade sob perspectivas mais estáticas ou mais dinâmicas [...] Talvez se encontre nisso a "magia do etnógrafo": na transformação de uma massa caótica de dados [...], convertida finalmente em um discurso coerente e unitário, no qual cada dado não apenas se encaixa em um segmento apropriado do discurso mas também vai se mostrando multirreferido para os demais até conseguir apresentar uma cultura como um todo (VELASCO; DÍAZ DE RADA, 1997, p. 32, 36).
\end{abstract}

Quando tratamos de contextos em relação aos livros escolares, nos referimos a uma variedade de marcos de referência que dão sentido aos textos. Estes contextos, certamente, se referem tanto ao ambiente escolar como ao extraescolar. Kira Mahamud, na sua tese de doutorado que mencionamos acima, aborda os textos escolares considerando tanto seu contexto de produção com seu contexto de uso ou recepção. Para reconstruir o contexto do uso ou recepção recorre ao marco escolar, utilizando os cadernos dos alunos como via para conhecer as formas de uso dos manuais escolares em sala de aula. Ao inverso, para o contexto de produção considera aspectos externos à escola, incluindo tanto o marco sócio histórico como a concepção da escola primária do período que estudou. A contribuição mais interessante neste aspecto é que para o marco sócio histórico a autora leva em conta o que denomina como "clima" da época, que na sua pesquisa se refere a "climas emocionais", ou seja, questiona qual grau de associação ou dissociação existe entre os sentimentos e emoções que prevaleciam na sociedade da pós-guerra espanhola (fome, medo, ódio, tristeza...) e aqueles encontrados nos manuais escolares. Para reconstruir esse "clima" utiliza sobretudo fontes literárias autobiográficas, acrescentando também relatos sobre a vida cotidiana da época. Por outro lado, analisa os discursos que rondavam a escola e dos que se nutriram os autores dos textos escolares (discursos de personalidades relevantes, documentos legislativos, manuais de formação de professores, entre outros) (MAHAMUD, 2012, p. 153-215).

Outro exemplo interessante de reconstrução do contexto extraescolar nos oferece Ana Maria Badanelli ao estudar os manuais escolares espanhóis de religião do período 1900-1970, que se caracterizaram pela abundância de ilustrações. Banadelli chama a atenção de como, em geral, a Igreja católica recorreu a todo tipo de imagens (pintura, escultura, lâminas, cartões) como recurso de comunicação pedagógica, pelo qual não é estranho que estas imagens entraram também como elemento de destaque nos textos 
escolares de Religião e nas salas de aula (BADANELLI, 2012, p. 315). Por outra parte, José María González Clouté relaciona a imagem da energia nuclear transmitida pelos textos escolares de Física e Química na segunda metade do século XX, com a visão que davam ao cinema e aos quadrinhos sobre a mesma questão na época e mostra contradições entre os manuais escolares e o contexto extraescolar (GONZÁLEZ CLOUTÉ, 2011).

A reconstrução dos contextos que dão significado aos manuais escolares tem sempre a pretensão de abarcar a totalidade dos elementos que explicam o manual como parte da cultura escolar. Como já afirmamos acima, estas contextualizações são difíceis porque requerem o uso de fontes complexas e nem sempre acessíveis. Não obstante, a apreensão da totalidade deve ser sempre uma tendência: "seria mais sensato, e talvez mais estimulante, assumir o caráter sempre incompleto - e não só fragmentário - da pesquisa, mantendo porém intactas as aspirações à apreensão da totalidade, como atitude teórica e crítica" (VELASCO; DÍAZ DE RADA, 1997, p. 39).

\section{CONSIDERAÇÕES FINAIS}

Queremos descortinar algumas questões metodológicas que tem afetado a pesquisa histórica sobre os textos escolares nos últimos vinte anos, sinalizando uma série de inquietações que, com duas décadas de perspectivas, nos indicam caminhos a seguir e outros a evitar. Não pretendíamos esgotar todas as possíveis abordagens de pesquisa de que é suscetível o texto escolar utilizado como fonte histórica, mas quisemos destacar os problemas mais recorrentes que apresentam a manualística como campo de pesquisa.

O estudo dos textos escolares como um objeto de valor comercial, a indagação sobre os autores dos textos escolares no processo de profissionalização dos professores e pedagogos (OSSENBACH, 2011), ou as virtudes e dificuldades da análise comparativa e transnacional dos manuais escolares (CHOPPIN, 2008) são alguns outros temas relevantes sobre os quais é preciso avançar na pesquisa, com premissas metodológicas bem fundamentadas.

\section{REFERÊNCIAS}

ARAGÓN, Santiago. La reflexión semántica: primera etapa en el proceso de informatización de una colección universitaria de Ciencias Naturales con vocación pedagógica. Ponencia inédita, Madri, Centro de Ciencias Humanas y Sociales-CSIC, fev. 2009.

BADANELLI, Ana María. Representing two worlds: illustrations in Spanish textbooks for the teaching of religion and object lessons (1900-1970), History of Education, 41:3, p. 303-338, 2012. 
BADANELLI, Ana María; OSSENBACH, Gabriela. Making History in the Digital Age: new forms of access to the sources and of preservation of the historicaleducational heritage, History of Education \& Children's Literature, V, 1, p. 79-91, 2010.

BOCARDO, Enrique. El giro contextual: cinco ensayos de Quentin Skinner, y seis comentarios, Madri, Tecnos, 2007.

CHARTIER, Roger. La mediación editorial. In: Las revoluciones de la cultura escrita: Diálogo e intervenciones, Barcelona, Gedisa, 2000.

CHOPPIN, Allain. Le manuel scolaire, une fausse évidence historique, Histoire de l'Éducation, 117, p. 7-56, 2008.

DEPAEPE, Marc; SIMON, Frank. Schulbücher als Quellen einer dritten Dimension in der Realitätsgeschichte von Erziehung und Unterricht. Über neue Konzeptionen in der historisch-pädagogischen Schulbuchforschung. In: WIATER, W. Schulbuchforschung in Europa. Bestandaufnahme und Zukunftsperspektive, Bad Heilbrun, Verlag Julius Klinkhardt, 2003.

DEPAEPE, Marc; VAN GORP, Angelo. Introduction: In Search of the Real Nature of Textbooks. In: VAN GORP, A.; DEPAEPE, M. Auf der Suche nach der wahren Art von Textbüchern, Bad Heilbrunn, Verlag Julius Klinkhardt, p. 17-23, 2009.

ECO, Umberto. Lector in Fabula. La cooperación interpretativa en el texto narrativo, Barcelona, Lumen, 1999.

GONZÁLEZ CLOUTÉ, José María. El imaginario social de la radiactividad y la energía nuclear en los manuales escolares españoles de Física y Química durante la segunda mitad del siglo XX. Tese (Doutorado) dirigida por Miguel Somoza Rodríguez, UNED, Faculdade de Educação, Madri, 2011.

HEINZE, Carsten. Historical Textbook Research: Textbooks in the Context of the 'Grammar of Schooling', Journal of Educational Media, Memory and Society, 2:2, 2010, p. 122.

HERNÁNDEZ LAILLE, Margarita. Darwinismo y manuales escolares en España e Inglaterra en el siglo XIX, 1870-1902, Madrid, UNED, 2010.

JULIA, Dominique. La culture scolaire comme objet historique, Paedagogica Historica. Supplementary Series, I, 1995. 
MAHAMUD, Kira. Adoctrinamiento emocional y socialización política en el primer franquismo (1939-1959). Emociones y sentimientos en los manuales escolares de enseñanza primaria, Tese (Doutorado) dirigida por Manuel de Puelles Benítez, UNED, Faculdade de Educação, Madri, 2012.

MEDA, Juri; BADANELLI, Ana Maria (org.). La historia de la cultura escolar en Italia y en Espana: balance y perspectivas. Macerata (Itália), EUM, 2013.

MORA LUNA, Antonia María. La educación literaria en la España contemporánea. Curricula educativos y manualística escolar para la construcción de identidades (19702006), Tese (Doutorado) dirigida por Miguel Beas Miranda y Miguel Ángel García, Universidade de Granada, Faculdade de Ciências da Educação, Granada, 2012.

OSSENBACH, Gabriela. Los docentes como autores y usuarios de manuales escolares. In: CELADA PERANDONES, Pablo (ed.), Arte y oficio de enseñar. Dos siglos de perspectiva histórica. XVI Coloquio Nacional de Historia de la Educación, El Burgo de Osma, Sociedad Española de Historia de la Educación/ Universidad de Valladolid/ Centro Internacional de la Cultura Escolar, vol. II, p. 281-287, 2011.

OSSENBACH, Gabriela; DEPAPE, Marc; SIMON, Frank; SOMOZA, Miguel; BADANELLI, Ana Maria. Le Réseau PATRE-MANES: une expérience d'intégration de bases de données de manuels scolaires Européens et Latino-Américains et ses implications pour la 'nouvelle' Historie de l'Éducation Culturelle. Comunicação apresentada no colóquio internacional Le manuel scolaire d'ici et d'ailleurs, d'hier à demain, Quebec (Canadá), abril 2006.

ROCKWELL, Elsie. Entre la vida y los libros: prácticas de lectura en las escuelas de la Malintzi a principios del siglo XX. In: CASTAÑEDA, C. et al. (coords.), Lecturas y lectores en la Historia de México, México, CIESAS/ Universidade Autónoma do Estado de Morelos, 2004.

. La experiencia etnográfica. Buenos Aires, Paidós, 2009.

VELASCO, Honorio; DÍAZ DE RADA, Ángel. La lógica de la investigación etnográfica. Un modelo de trabajo para etnógrafos de la escuela. Madri, Trotta, 1997.

VIÑAO FRAGO, Antonio. Lenguaje y realidad. El discurso histórico y su aplicación al ámbito histórico-educativo, Anales de Pedagogía, 14, pp. 158- 172, 1996.

. El libro de texto y las disciplinas escolares: una mirada a sus orígenes. In: ESCOLANO, Agustín (ed.), Currículum editado y sociedad del 
conocimiento. Texto, multimedialidad y cultura de la escuela, Valencia, Tirant lo Blanch, 2006a.

. La historia de las disciplinas escolares, Historia de la Educación. Revista Interuniversitaria”, 25, pp. 243-269, 2006b. (Tradução portuguesa en Revista Brasileira de História da Educação, 18, pp. 173-215, 2008).

Recebido: $10 / 03 / 2017$

Aprovado: 20/04/2017 